\title{
Complex organic matter in Titan's atmospheric aerosols from in situ pyrolysis and analysis
}

\author{
G. Israël ${ }^{1}$, C. Szopa ${ }^{1}$, F. Raulin ${ }^{2}$, M. Cabane ${ }^{1}$, H. B. Niemann ${ }^{3}$, S. K. Atreya ${ }^{4}$, S. J. Bauer ${ }^{5}$, J.-F. Brun ${ }^{1}$, \\ E. Chassefière ${ }^{1}$, P. Coll ${ }^{2}$, E. Condé ${ }^{6}$, D. Coscia ${ }^{2}$, A. Hauchecorne ${ }^{1}$, P. Millian ${ }^{7}$, M.-J. Nguyen ${ }^{2}$, T. Owen ${ }^{8}$, \\ W. Riedler ${ }^{9}$, R. E. Samuelson ${ }^{10}$, J.-M. Siguier ${ }^{7}$, M. Steller ${ }^{11}$, R. Sternberg ${ }^{2}$ \& C. Vidal-Madjar ${ }^{12}$
}

Aerosols in Titan's atmosphere play an important role in determining its thermal structure ${ }^{1-3}$. They also serve as sinks for organic vapours ${ }^{4}$ and can act as condensation nuclei for the formation of clouds ${ }^{5,6}$, where the condensation efficiency will depend on the chemical composition of the aerosols ${ }^{5,7}$. So far, however, no direct information has been available on the chemical composition of these particles. Here we report an in situ chemical analysis of Titan's aerosols by pyrolysis at $600{ }^{\circ} \mathrm{C}$. Ammonia $\left(\mathrm{NH}_{3}\right)$ and hydrogen cyanide (HCN) have been identified as the main pyrolysis products. This clearly shows that the aerosol particles include a solid organic refractory core. $\mathrm{NH}_{3}$ and $\mathrm{HCN}$ are gaseous chemical fingerprints of the complex organics that constitute this core, and their presence demonstrates that carbon and nitrogen are in the aerosols.

Although the Gas Chromatograph and Mass Spectrometer (GCMS) was primarily devoted to the analysis of atmospheric gases $^{8}$, it was also used for the analysis of vaporized particulates through coupling to the Aerosol Collector and Pyrolyser (ACP) experiment. The ACP instrument ${ }^{9,10}$ collected two distinct atmospheric samples over separate altitude ranges $(130-35 \mathrm{~km}$ and $25-$ $20 \mathrm{~km}$, respectively) during the Huygens probe descent (see Supplementary Information). The composition of each sample was analysed by the GCMS in three stages (see Table 1). First, the most volatile part of a given sample was analysed by the GCMS at 'ambient' collection temperature. Second, the remaining part of the sample was heated in the ACP oven to $250^{\circ} \mathrm{C}$ in order to vaporize all volatile components of the collected aerosols, and analysis of the gaseous products was then carried out. Last, the remainder of the sample was subjected in the oven to a temperature of $600^{\circ} \mathrm{C}$. The high temperature in this last stage ensured that the refractory material composing the aerosol particles was thermally decomposed (pyrolysed) into molecular gaseous products. These products contribute to the composition of the gaseous sample to be analysed by GCMS. An in-depth technical description of the ACP experiment and its coupling with the GCMS has been given in earlier articles ${ }^{9-11}$. Relevant temperatures and altitudes during descent are also given in Table 1.

In this report we focus on the composition of the refractory material making up the collected aerosols, and hence restrict our attention to the third stage of the analysis, in which the sample is heated to $600{ }^{\circ} \mathrm{C}$ before transferring the gaseous products of pyrolysis to the GCMS. Only data obtained using the direct Mass Spectrometry (MS) mode are analysed here. As explained in the companion paper, all data related to the gas chromatograph part of the GCMS will be reported later. In the obtained spectra, values of mass to charge ratio $(\mathrm{m} / \mathrm{z})$ above 50 are close to the noise level and are difficult to determine. We therefore restrict our analysis to the range $m / z=2-50$.

Results from the transfer of the evolved gases to the GCMS experiment after heating the samples at $600^{\circ} \mathrm{C}$ are compared with results for the reference background in Figs 1 and 2. Two of the most noticeable enhancements of signal for the transfer samples (that are not associated with molecular nitrogen) are those at $\mathrm{m} / z=17$ and 27.

Mass spectra measured during the transfer of the gases that evolved from the first aerosol sample (after pyrolysis at $600^{\circ} \mathrm{C}$ ) reveal a pyrolysis fragment feature at $m / z=17$ (Fig. 1). According to the National Institute of Standards and Technology (NIST) library on mass spectrometry, this specific feature can be attributed to $\mathrm{CH}_{3} \mathrm{D}$,

${ }^{13} \mathrm{CH}_{4}$ or $\mathrm{NH}_{3}$. A comparison of relative strengths of the features at $m / z=16$ and $m / z=17$ indicates that $\mathrm{CH}_{3} \mathrm{D}$ must have no noticeable contribution at $m / z=17$, given the known $\mathrm{D} / \mathrm{H}$ ratio in Titan's atmosphere (about $(2.3 \pm 0.5) \times 10^{-4}$; ref. 12$) .{ }^{13} \mathrm{CH}_{4}$ must contribute, but if the $m / z=17$ signal was entirely due to this compound, our data would provide a ${ }^{12} \mathrm{C} /{ }^{13} \mathrm{C}$ ratio of 48 . This is much lower than the value of 82.3 measured in the gas phase by the GCMS. It would then correspond to an unexplainable isotopic enrichment in ${ }^{13} \mathrm{C}$ in the aerosols when compared with the gaseous phase, whereas it is expected that kinetically driven chemical processes favour ${ }^{12} \mathrm{C}$ insertion, as already observed in laboratory experiments ${ }^{13}$. Consequently, the $m / z=17$ signature must be attributed to another species, in combination with the contribution of ${ }^{13} \mathrm{CH}_{4}$. The only possible candidate for this contribution is $\mathrm{NH}_{3}$. A similar interpretation can be made for the $m / z=17$ feature in Fig. 2. In this case, the ${ }^{12} \mathrm{C} /{ }^{13} \mathrm{C}$ ratio is 56 . Finally, further evidence can be seen in Fig. 3a and $\mathrm{b}$, where the evolution of the signal at $\mathrm{m} / z=16$ and $\mathrm{m} / z=17$ respectively, during the transfer of the gases evolved from the second sample pyrolysed at $600^{\circ} \mathrm{C}$, strongly favours identification of ammonia.

When the second aerosol sample is pyrolysed at $600{ }^{\circ} \mathrm{C}$ (Fig. 2), the signal intensity increases, compared with the signal presented in Fig. 1, possibly owing to the collection of a larger number of particles; in addition, a pyrolysis fragment feature that was lost in the background in Fig. 1 appears in Fig. 2 at $m / z=27$. The NIST library molecular fragment list suggests that several compounds may contribute to this feature at $m / z=27$. These compounds are $\mathrm{C}_{2} \mathrm{H}_{4}$, 
Table 1 Results for the two aerosol samples collected and analysed by ACP

\begin{tabular}{|c|c|c|c|c|c|c|}
\hline Parameters & \multicolumn{3}{|c|}{ Sample 1} & \multicolumn{3}{|c|}{ Sample 2} \\
\hline Sampling altitudes $(\mathrm{km})$ & \multirow{2}{*}{\multicolumn{3}{|c|}{$\begin{array}{c}130-35 \\
3-176\end{array}$}} & \multirow{2}{*}{\multicolumn{3}{|c|}{$\begin{array}{c}25-20 \\
320-430\end{array}$}} \\
\hline Atmospheric pressure (mbar) & & & & & & \\
\hline Analysis altitudes $(\mathrm{km})$ & 32 & 30 & 27 & 16 & 15 & 13 \\
\hline Atmospheric pressure (mbar) & 250 & 275 & 325 & 640 & 685 & 760 \\
\hline Sample temperature in the $\mathrm{ACP}$ oven $\left({ }^{\circ} \mathrm{C}\right)^{\star}$ & 'Ambient': -120 to -90 & 250 & 600 & -74 & 250 & 600 \\
\hline
\end{tabular}

Altitudes corresponding to sampling and analysis were provided by the HASI experiment. All samples were analysed using direct mass spectrometry measurements with the Huygens GCMS instrument.

Values are $\pm 10^{\circ} \mathrm{C}$

$\mathrm{C}_{2} \mathrm{H}_{6}, \mathrm{C}_{3} \mathrm{H}_{8}$ and $\mathrm{HCN}$. The main fragments of $\mathrm{C}_{2} \mathrm{H}_{4}, \mathrm{C}_{2} \mathrm{H}_{6}$ and $\mathrm{C}_{3} \mathrm{H}_{8}$ detected by MS are observed at $\mathrm{m} / z=28$ and 29 according to the NIST library. As the atmospheric nitrogen, and the labelled molecular nitrogen ${ }^{15} \mathrm{~N}^{15} \mathrm{~N}$ used in ACP, are strong contributors to the signal obtained at these $\mathrm{m} / z$ values, it is not possible to point out the presence of $\mathrm{C}_{2} \mathrm{H}_{4}, \mathrm{C}_{2} \mathrm{H}_{6}$ and $\mathrm{C}_{3} \mathrm{H}_{8}$ with these features. However, if these compounds were contributing to the feature at $m / z=27$, we should see a noticeable contribution of the $\mathrm{C}_{2}$ hydrocarbons at $m / z=26$ and noticeable contributions of $\mathrm{C}_{3} \mathrm{H}_{8}$ at $m / z=39,41$ and 43. In the present case, the pyrolysis feature at $\mathrm{m} / z=26$ is much smaller than that at $\mathrm{m} / z=27$, and no features are evident at $m / z=39,41$ and 43 . We conclude (although it is not easy to verify this owing to the poor resolution of the Mass Spectrometer) that $\mathrm{HCN}$ is the main contributor to the feature at $\mathrm{m} / z=27$ in the same way that $\mathrm{NH}_{3}$ is the dominant contributor to the feature at $\mathrm{m} / z=17$.

If these organic molecules had simply been condensed onto aerosol particles, they would have been driven off during the second analysis stage (at $250^{\circ} \mathrm{C}$ ) and further cleaning of the oven. We can therefore conclude that the $\mathrm{NH}_{3}$ and $\mathrm{HCN}$ observed in the third stage are pyrolysis products from the refractory aerosol material itself. This is confirmed by the fact that the GCMS experiment did not observe

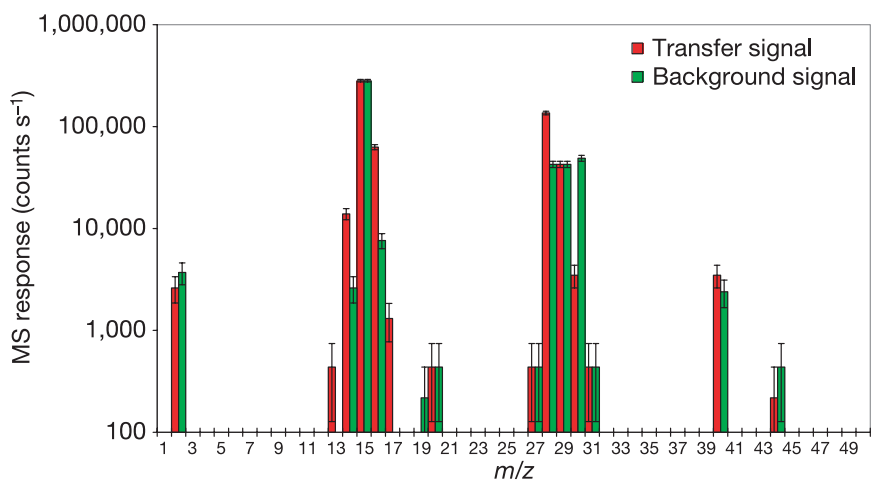

Figure 1 | Signal resulting from the mass spectrometry (MS) analysis of the gases evolved from pyrolysis of the first aerosol sample. Red, ion count rates per second versus mass per unit charge $(\mathrm{m} / \mathrm{z})$ measured during the transfer of the gases evolved from the first aerosol sample pyrolysed at $600^{\circ} \mathrm{C}$, and green, its corresponding background. Mass scans from $\mathrm{m} / z=2$ to 141 are acquired in unit mass steps every $0.937 \mathrm{~s}$. One count on the detector during the acquisition is equal to 217.7 counts s ${ }^{-1}$. Labelled ${ }^{15} \mathrm{~N}^{15} \mathrm{~N}$ is used to achieve the gas transfers from ACP to GCMS. Error bars represent \pm one standard deviation. After completion of the heating cycle, and transfer of gaseous pyrolysis products to the GCMS for analysis, the ACP oven is vented to the atmosphere and the background gas measurements are undertaken by GCMS. Thus, atmospheric gases contribute to the background signal along with the main ${ }^{15} \mathrm{~N}^{15} \mathrm{~N}$ carrier gas. The signals at $m / z=14,15$ and 16 can be mainly ascribed to methane, and to ${ }^{14} \mathrm{~N}^{14} \mathrm{~N}$ (for $m / z=14$ ) and ${ }^{15} \mathrm{~N}^{15} \mathrm{~N}$ (for $m / z=15$ ). The intensity of the feature at $\mathrm{m} / z=17$ increases from 0 counts $\mathrm{s}^{-1}$ (background) to 1,306 counts $\mathrm{s}^{-1}$ (analysis), demonstrating that the molecule responsible is a pyrolysis product. Analysis of the $\mathrm{m} / z=17$ signal demonstrates a contribution of $\mathrm{NH}_{3}$ in addition to that of ${ }^{13} \mathrm{CH}_{4}$.
$\mathrm{NH}_{3}$ and HCN in its atmospheric sampling ${ }^{8}$. This ACP result, predicted by theoretical models ${ }^{4}$, is of prime importance, as it is the first evidence of the presence of complex macromolecular organic matter in Titan's atmosphere.

Possible chemical pathways proposed for the production of aerosols from the gaseous chemistry,12 are: (1) polymerization of $\mathrm{C}_{2} \mathrm{H}_{2}$; (2) polymerization of nitriles; (3) formation of polyaromatic molecules; and (4) copolymerization (aliphatic and aromatic). Our data clearly indicate that nitrogen is incorporated into the chemical structure of Titan's aerosols, ruling out the possibility that these aerosols consist solely of polyacetylenes or other pure hydrocarbon compounds. To go further in the determination of Titan aerosol production pathways, one needs to rely on data obtained from experimental simulations-either by photochemistry ${ }^{14,15}$ or cold plasma discharges ${ }^{16-19}$ - that provide laboratory analogues (called

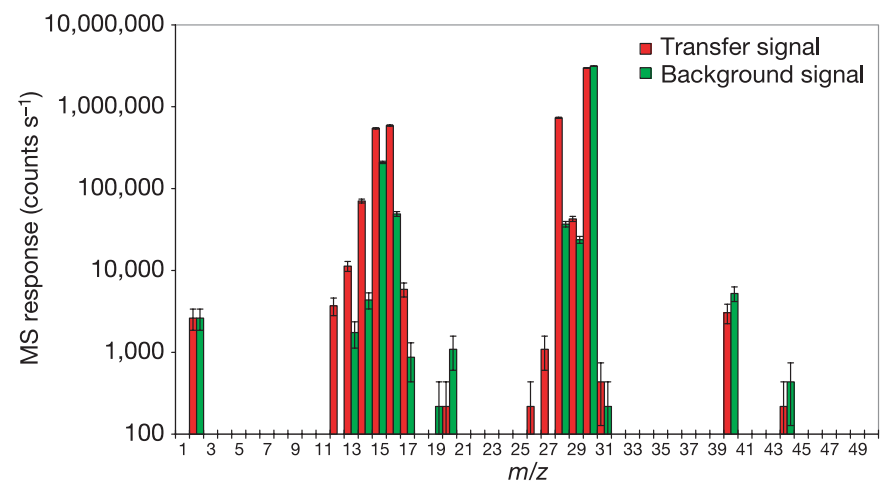

Figure 2 Signal resulting from the MS analysis of the gases evolved from pyrolysis of the second aerosol sample. Red and green, as for Fig. 1 but for the second aerosol sample; error bars represent \pm one standard deviation. In these spectra, and according to the measurements made by the GCMS ${ }^{9}$, features at $\mathrm{m} / z=40$ and $\mathrm{m} / z=44$ must be attributed respectively to instrument background ${ }^{40} \mathrm{Ar}$ and $\mathrm{CO}_{2}$. The features at $m / z=28$ and 30 can be attributed mainly to ${ }^{14} \mathrm{~N}^{14} \mathrm{~N}$ and ${ }^{15} \mathrm{~N}^{15} \mathrm{~N}$, respectively. The fragment at $m / z=17$ is enhanced (from 1,306 to 7,000 counts s$^{-1}$ ), which might be attributed to a greater amount of aerosols collected during the second ACP aerosol sampling. Furthermore, a potential pyrolysis fragment feature appears at $m / z=27$, the intensity of which increases from 0 (background) to 1,100 counts $^{-1}$ (analysis signal) on the spectra; on Fig. 1, this feature was obviously lost in the background. Although the NIST library molecular fragment list suggests that several compounds $\left(\mathrm{C}_{2} \mathrm{H}_{4}, \mathrm{C}_{2} \mathrm{H}_{6}, \mathrm{C}_{3} \mathrm{H}_{8}\right.$ and $\mathrm{HCN}$ ) may contribute to this feature at $m / z=27$, a chain of deduction (see main text) allows us to conclude that $\mathrm{HCN}$ is the main contributor to the feature at $m / z=27$. It is possible that there is instrumental crosstalk between adjacent features at $\mathrm{m} / z=27$ and 28 ; that is, some ions with $m / z=28$ can be detected at $m / z=27$, as observed by the GCMS experiment ${ }^{9}$. This crosstalk should depend on the intensity of the $m / z=28$ signal and vary in proportion to it. In fact, we noticed a strongly varying $(m / z=28) /(m / z=27)$ ratio, which indicates that the crosstalk plays here a minor role (see Supplementary Fig. 5). An experimental confirmation is expected by performing the injection of $\mathrm{HCN}$ into the laboratory models of the ACP-GCMS experiments, identical to the models having flown on the Huygens probe. 
tholins) of Titan's aerosols. These tholins have optical properties similar to those of Titan's aerosols ${ }^{16}$, and the simulation experiments that produce them also yield a suite of organic gases qualitatively representative of the hydrocarbon and nitrile gases observed in Titan's stratosphere ${ }^{20}$.

A few important but limited pyrolysis-GCMS analyses of tholin material show the release of $\mathrm{NH}_{3}$ and $\mathrm{HCN}^{15,19,21}$, but a more detailed and systematic laboratory investigation is clearly needed.

Some limitations of the ACP-GCMS data are apparent. For example, as found in recent laboratory experiments (see Supplementary Fig. 1), a feature at $m / z=78$ is diagnostic of the main MS fragment of benzene, an aromatic compound expected to be present in Titan's aerosol according to certain chemical models ${ }^{4,12}$. As the data are not sufficiently reliable above $m / z=50$, such aromatics are not directly detectable. The best approach is to infer higher-mass products using quantitative analyses from laboratory experiments now in progress. In particular, the presence of $\mathrm{NH}_{3}$ in the pyrolysis
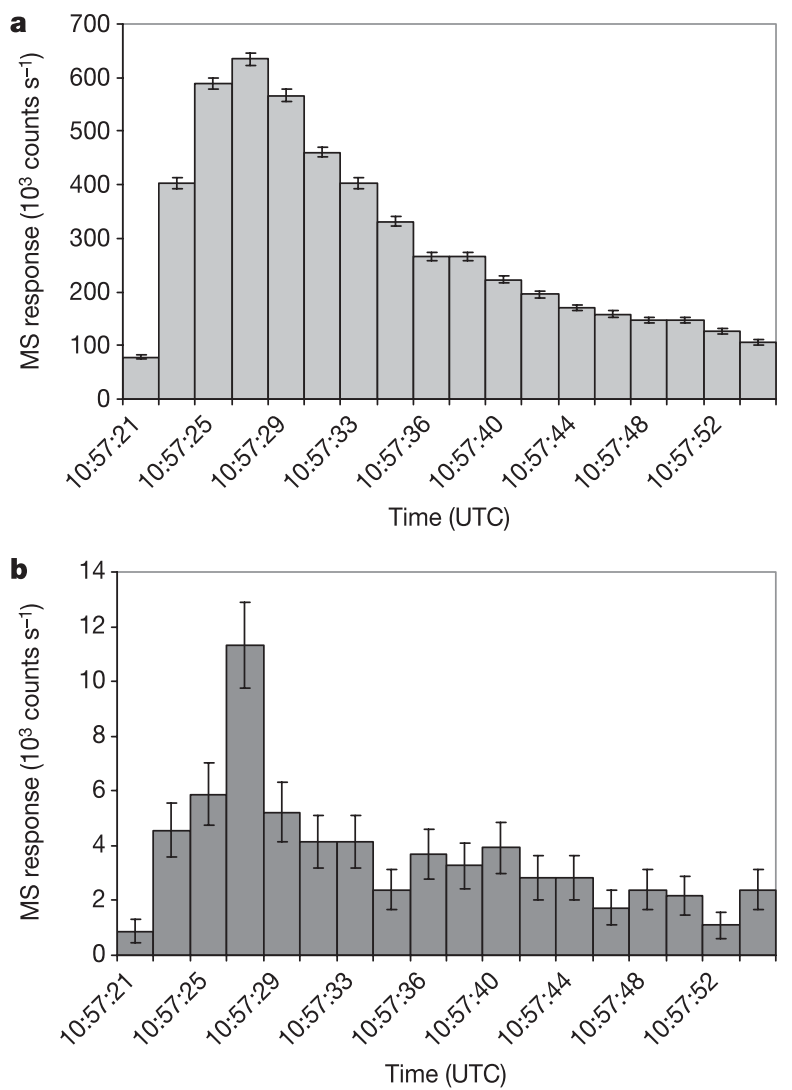

Figure 3 | Temporal evolution of the intensity of the MS signatures attributed to ammonia for the second aerosol sample pyrolysis. a, b, The temporal evolution of the signal for $m / z=16$ (a) and $m / z=17$ (b) during the transfer of the gases evolved from the second aerosol sample pyrolysis at $600{ }^{\circ} \mathrm{C}$ (named ACP 2-3). Error bars represent \pm one standard deviation $( \pm 1 \sigma)$ to the experimental value measured. A signature at $m / z=17$ is observed on the mass spectra measured during the transfer of the gases evolved from the first and the second aerosol samples pyrolysed at $600^{\circ} \mathrm{C}$ (see Figs 1 and 2). The rate at which the signal of the feature builds during successive sweeps of the MS decays with time. This is characteristic of a real signal, and not of noise (if the event at $m / z=17$ was due to noise, its intensity would not decrease with time during the successive injections in the MS). As seen on this figure, during the considered transfer, the signal at $m / z=17$ evolves in the same way as the signal at $m / z=16$ during ACP 2-3 transfer. However this behaviour cannot be explained by the contribution of the ${ }^{13} \mathrm{CH}_{4}$ alone. It requires the contribution of another species. Taking into account the distribution of the mass spectrum and the NIST MS library, the only possible candidate is $\mathrm{NH}_{3}$. A similar behaviour is observed on the mass spectra measured during the transfer of the gases evolved from the first aerosol sample pyrolysis at $600{ }^{\circ} \mathrm{C}$. products provides information about the general class of aerosols in Titan's atmosphere. Analytic diagnoses of some tholins have indicated the presence of the $\mathrm{NH}_{2}$ chemical group, which should be the major contributor to $\mathrm{NH}_{3}$ released by pyrolysis (see Supplementary Information, Section 3). Evidence supporting this idea has been obtained from recent mass spectrometric measurements ${ }^{22}$. The presence of $\mathrm{HCN}$ is less informative, as this molecule is generally observed in the thermal decomposition of polymeric species that include nitrile $\mathrm{CN}$ chemical groups or structural CN bonds ${ }^{23,24}$ (see Supplementary Information, Section 3). The presence of both $\mathrm{NH}_{3}$ and HCN does demonstrate, however, that nitrogen can be incorporated into Titan's aerosol in different ways, and the general presence of nitrogen in the aerosol suggests that the aerosol acts as an important sink for atmospheric nitrogen ${ }^{25}$.

Finally, our measurements do not indicate any substantial difference between the two samples collected at different altitudes, covering the range from the middle stratosphere down to the middle troposphere. This is consistent with an aerosol of homogeneous composition between altitudes of 130 and $20 \mathrm{~km}$, suggesting a common source. Such a source is generally associated with a photochemical production layer well above $200 \mathrm{~km}$ (ref. 7). From this upper region of the atmosphere the aerosol is transported to lower levels by diffusion, precipitation and atmospheric circulation.

The results presented here show that the complex organic matter produced by Titan's atmospheric chemistry is being carried irreversibly to the surface by the aerosols. This material should thus contribute to the composition of the surface and to its spectral signatures, in particular in the infrared range. Other complementary information on the optical and radiometric properties of the aerosols can be obtained from the Descent Imager/Spectral Radiometer instrument ${ }^{26}$ on the Huygens probe, and from the Visible and Infrared Mapping Spectrometer and the Composite Infrared Spectrometer on board the Cassini spacecraft.

Received 27 May; accepted 20 October 2005.

Published online 30 November 2005

1. McKay, C. P., Pollack, J. B. \& Courtin, R. The greenhouse and antigreenhouse effects on Titan. Science 253, 1118-1121 (1991).

2. Rannou, P., Hourdin, F., McKay, C. P. \& Luz, D. A coupled dynamicsmicrophysics model of Titan's atmosphere. Icarus 170, 443-462 (2004).

3. DelGenio, A. D., Zhou, W. \& Eichler, T. P. Equatorial superrotation in a slowly rotating GCM - Implications for Titan and Venus. Icarus 101, 1-17 (1993).

4. Lebonnois, S., Bakes, E. L. O. \& McKay, C. P. Transition from gaseous compounds to aerosols in Titan's atmosphere. Icarus 159, 505-517 (2002).

5. Barth, E. L. \& Toon, O. W. Properties of methane clouds on Titan: results from microphysical modelling. Geophys. Res. Lett. 31, L17S07 (2004).

6. Mayo, L. A. \& Samuelson, R. E. Condensate clouds in Titan's north polar stratosphere. Icarus 176, 316-330 (2005).

7. McKay, C. P. et al. Physical properties of the organic aerosols and clouds of Titan. Planet. Space Sci. 49, 79-99 (2001).

8. Niemann, H. et al. The abundances of constituents of Titan's atmosphere from the GCMS instrument on the Huygens probe. Nature doi:10.1038/nature04122 (this issue).

9. Israel, G., Cabane, M., Raulin, F., Chassefière, E. \& Boon, J. J. Aerosols in Titan's atmosphere: models, sampling techniques and chemical analysis. Ann. Geophys. 9, 1-13 (1991)

10. Israel, G. et al. Huygens Probe Aerosol Collector Pyrolyser Experiment. Space Sci. Rev. 104, 435-466 (2002).

11. Niemann, H. et al. The Gas Chromatograph Mass Spectrometer for the Huygens Probe. Space Sci. Rev. 104, 551-590 (2002).

12. Wilson, E. H. \& Atreya, S. K. Chemical sources of haze formation in Titan's atmosphere. Planet. Space Sci. 51, 1017-1033 (2003).

13. Chang, S., DesMarais, D., Mack, R., Miller, S. L. \& Strathearn, G. E. in Earth's Earliest Biosphere: Its Origin and Evolution (ed. Schopf, J. W.) 53-92 (Princeton Univ. Press, Princeton, 1982).

14. Bar-Nun, A., Kleinfeld, I. \& Ganor, E. Shape and optical properties of aerosols formed by photolysis of acetylene, ethylene and hydrogen cyanide. J. Geophys. Res. 93, 8383-8387 (1988).

15. Clarke, D. W. \& Ferris, J. P. Titan haze: structure and properties of cyanoacetylene and cyanoacetylene-acetylene photopolymers. Icarus 127, 158-172 (1997).

16. Khare, B. N. et al. Optical constants of organic tholins produced in a simulated titanian atmosphere: from X-ray to microwave frequencies. Icarus 60, 127-137 (1984) 
17. Coll, P. et al. Experimental laboratory simulation of Titan's atmosphere: aerosols and gas phase. Planet. Space Sci. 47, 1331-1340 (1999).

18. Imanaka, H. et al. Laboratory experiments of Titan tholins formed in cold plasma at various pressures: implications for nitrogen containing polycyclic aromatic compounds in Titan haze. Icarus 168, 344-366 (2004).

19. Khare, B. N. et al. The organic aerosols of Titan. Adv. Space Res. 4, 59-68 (1984).

20. Coll, P., Coscia, D., Gazeau, M.-C., Guez, L. \& Raulin, F. Review and latest results of laboratory investigations of Titan's aerosols. Orig. Life Evol. Biosph. 28, 195-213 (1997).

21. Ehrenfreund, P. et al. Analytical pyrolysis experiments of Titan aerosol analogues in preparation for the Cassini Huygens mission. Adv. Space Res. 15, 335-342 (1995).

22. Somogyi, A., Oh, C.-H., Smith, M. A. \& Lunine, J. I. Organic environments on Saturn's moon, Titan: simulating chemical reactions and analysing products by FT-ICR and ion trap mass spectrometry. J. Am. Soc. Mass Spectrom. 16, 850-859 (2005).

23. Thompson, W. R., Henry, T. J., Schwartz, J. M., Khare, B. N. \& Sagan, C. Plasma discharge in $\mathrm{N}_{2}+\mathrm{CH}_{4}$ at low pressures: experimental results and applications to Titan. Icarus 90, 57-73 (1991).

24. Minard, R. D., Hatcher, P. G., Gourley, R. C. \& Matthews, C. N. Structural investigations of hydrogen cyanide polymers: new insights using TMAH thermochemolysis/GC-MS. Orig. Life Evol. Biosph. 28, 461-473 (1998).

25. McKay, C. P. Elemental composition, solubility, and optical properties of Titan's organic haze. Planet. Space Sci. 44, 741-747 (1996).
26. Tomasko, M. G. et al. Rain, winds and haze during the Huygens probe's descent to Titan's surface. Nature doi:10.1038/nature04126 (this issue).

Supplementary Information is linked to the online version of the paper at www.nature.com/nature.

Acknowledgements We acknowledge financial support from CNES, CNRS, the Austrian Ministry of Research and NASA. For the fabrication and qualification of ACP's mechanical and pneumatic components, the prime industrial contractor was SNECMA, and we acknowledge CNES Toulouse who strongly supported the CNRS ACP team. In particular, we thank C. Gelas, R. Salomé and E. Condé. We also thank the other main contractors, The Joanneum Research Institute and Austrian Aerospace, for the quality of their work. We acknowledge the support of the following people during the development of the instrument: M.-C. Gazeau and the LISA team at Créteil, R. Sablé and the ONERA/CERT in Toulouse, C. Cordelle and F. Marchandise at SNECMA, and G. Zeynard at Austrian Aerospace. We are also much indebted to the ESA Huygens Project Team for its constant support.

Author Information Reprints and permissions information is available at npg.nature.com/reprintsandpermissions. The authors declare no competing financial interests. Correspondence and requests for materials should be addressed to G.I. (Guy.israel@aerov.jussieu.fr). 